\title{
Potential mechanism prediction of Cold-Damp Plague Formula against COVID-19 via network pharmacology analysis and molecular docking
}

Lin $\mathrm{Han}^{1+}{ }^{1}$, Xiu-Xiu Wei ${ }^{2+}$, Yu-Jiao Zheng ${ }^{2+}$, Li-Li Zhang ${ }^{1}$, Xin-Miao Wang ${ }^{1}$, Hao-Yu Yang ${ }^{2}$, Xu Ma ${ }^{3}$, Lin-Hua Zhao ${ }^{{ }^{*}}$ and Xiao-Lin Tong ${ }^{1^{*}}$

\begin{abstract}
Background: Coronavirus disease 2019 (COVID-19) is a new global public health emergency. The therapeutic benefits of Cold-Damp Plague Formula (CDPF) against COVID-19, which was used to treat "cold-dampness stagnation in the lung" in Trial Versions 6 and 7 of the "Diagnosis and Treatment Protocol for COVID-19", have been demonstrated, but the effective components and their mechanism of action remain unclear.

Methods: In this study, a network pharmacology approach was employed, including drug-likeness evaluation, oral bioavailability prediction, protein-protein interaction (PPI) network construction and analysis, Gene Ontology (GO) terms, and Kyoto Encyclopedia of Genes and Genomes (KEGG) pathway annotation, and virtual docking, to predict the bioactive components, potential targets, and molecular mechanism of CDPF for COVID-19 treatment.

Results: The active compound of herbs in CDPF and their candidate targets were obtained through database mining, and an herbs - ingredients - targets network was constructed. Subsequently, the candidate targets of the active compounds were compared to those relevant to COVID-19, to identify the potential targets of CDPF for COVID-19 treatment. Subsequently, the PPI network was constructed, which provided a basis for cluster analysis and hub gene screening. The seed targets in the most significant module were selected for further functional annotation. GO enrichment analysis identified four main areas: (1) cellular responses to external stimuli, (2) regulation of blood production and circulation, (3) free radical regulation, (4) immune regulation and anti-inflammatory effects. KEGG pathway analysis also revealed that CDPF could play pharmacological roles against COVID-19 through "multi components-multi targets-multi pathways" at the molecular level, mainly involving anti-viral, immune-regulatory, and anti-inflammatory pathways; consequently, a "CDPF_herbs—ingredients—targets—pathways_COVID-19" network was constructed. In hub target analysis, the top hub target IL6, and ACE2, the receptor via which SARS-CoV-2 typically enters host cells, were selected for molecular docking analyses, and revealed good binding activities.
\end{abstract}

Conclusions: This study revealed the active ingredients and potential molecular mechanism by which CDPF treatment is effective against COVID-19, and provides a reference basis for the wider application and further mechanistic investigations of CDPF in the fight against COVID-19.

\footnotetext{
*Correspondence: melonzhao@163.com; tongxiaolin@vip.163.com

‘Lin Han, Xiu-Xiu Wei, and Yu-Jiao Zheng contributed equally to this work

${ }^{1}$ Guang'anmen Hospital, China Academy of Chinese Medical Sciences, Beijing 100053, China

Full list of author information is available at the end of the article
}

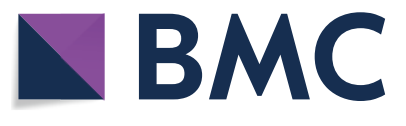

(c) The Author(s) 2020. This article is licensed under a Creative Commons Attribution 4.0 International License, which permits use, sharing, adaptation, distribution and reproduction in any medium or format, as long as you give appropriate credit to the original author(s) and the source, provide a link to the Creative Commons licence, and indicate if changes were made. The images or other third party material in this article are included in the article's Creative Commons licence, unless indicated otherwise in a credit line to the material. If material is not included in the article's Creative Commons licence and your intended use is not permitted by statutory regulation or exceeds the permitted use, you will need to obtain permission directly from the copyright holder. To view a copy of this licence, visit http://creativeco mmons.org/licenses/by/4.0/. The Creative Commons Public Domain Dedication waiver (http://creativecommons.org/publicdomain/ zero/1.0/) applies to the data made available in this article, unless otherwise stated in a credit line to the data. 
Keywords: COVID-19, Cold-Damp Plague Formula (CDPF), Network pharmacology, Molecular mechanism, Molecular docking

\section{Background}

Novel coronavirus pneumonia (NCP) is an infectious disease induced by severe acute respiratory syndrome coronavirus 2 (SARS-CoV-2), which is characterized by a long incubation period, rapid spread, and general population susceptibility. The disease may progress to pneumonia, acute respiratory distress syndrome, acute kidney injury, shock, and multi organ dysfunction [1]. Since January 2020, the virus spread rapidly to most parts of China as well as to other countries worldwide, and the World Health Organization (WHO) declared the disease outbreak as the sixth public health emergency of international concern on January 30, 2020 [2]. NCP was officially named coronavirus disease 2019 (COVID-19) by the WHO on February 11, 2020 [3]. As of May 1, 2020, data released by the WHO revealed 3,175,207 known cases of COVID-19, 224,172 reported deaths, and 211 affected countries or regions [4], these figures are updated daily and are expected to increase further. COVID-19 poses a marked threat to the safety and health of the world's population, and the global impact of the outbreak continues to expand. As no specific drug or vaccine against COVID-19 has been identified to date, creation of a rapid and effective prevention and control program, curbing the spread of disease, and reducing the damage caused by the pandemic are major challenges.

In its long history, Traditional Chinese Medicine (TCM) has accumulated a solid theoretical basis for the treatment of infectious diseases [5], and has recently been implemented against viral pneumonia. TCM have been reported to enhance the immunity of the organism, shorten the duration of treatment, and prevent complications according to numerous studies [6-10]. TCM showed a good treatment effect against severe acute respiratory syndrome (SARS) in 2003. Compared with pure Western medicine-treatment, treatment with pure Chinese herbal medicine could significantly shorten the average absorption time of the lung shadow, without any obvious complications in follow-up, in SARS patients [7]. In the COVID-19 epidemic, China has used a combination of Chinese and Western medicine for both the prevention and treatment of the disease, with notable positive effects. With the strong support of the Chinese government, TCM has been used in the treatment of 91.5\% of confirmed cases; inclusion of TCM in COVID19 treatment not only reduced the death rate of severe/ critical patients by more than $80 \%$, but also resulted in a low rate of relapse in recovered patients; the total effective rate of TCM is more than 90\% [11, 12]. Further, more and more studies have analyzed mechanisms of action of TCM formulae in treating COVID-19 [1317]. TCM has been recommended for different stages of COVID-19 treatment since the third trial version of the "Diagnosis and Treatment Protocol for COVID-19" published by National Health Commission of the People's Republic of China, along with Western standard treatment $[14,18]$.

In trial versions 6 and 7 of the "Diagnosis and Treatment Protocol for COVID-19," the Cold-Damp Plague Formula (CDPF) was recommended for treating "colddampness stagnation in the lung," as the disease was designated as a "cold-dampness pestilence" based on the clinical features of COVID-19 cases in Wuhan [19]. The formula was devised by academician Xiao-Lin Tong and other experts, particularly for use in suspected and earlystage confirmed COVID-19 cases, and was mainly used in the epicentre of the epidemic, Wuhan, as well as in other large epidemic areas [19-21]. CDPF, consisting of 20 herbs (Table 1), is based on several classical prescriptions, including Ma Xing Shi Gan decoction, Ting Li Da Zao Xie Fei decoction, Huo Po Xia Ling decoction, Shen Zhu San, and Da Yuan Yin, and has the TCM functions of ventilating the lungs and expelling pathogenic factors, dispelling toxins and dredging collaterals, dissolving turbidity, strengthening the spleen, and eliminating dampness [19]. More than 50,000 COVID-19 patients, including mild cases, moderate cases, suspected cases, and self-isolating fever cases, have taken CDPF, which showed significant advantages in improving the cure rate, reducing mortality, and promoting physical recovery $[12$, 22].

The effect of TCM is related to the mechanism of the multi-ingredients, multi-targets, and multi-pathways of herbs; however, this multi-faceted mechanism makes it difficult to identify the mechanism of action of CDPF in terms of traditional pharmacological evaluation. On the other hand, network pharmacology is an effective approach to study and clarify the mechanism of drug action, which could explain the mechanism of functional drugs based on a network of public databases or data obtained through early studies. The network pharmacology research strategy is in line with the understanding of disease integrity in TCM $[23,24]$.

Thus, in this study, we utilized network pharmacology and the related technology to explore the main bioactive components of CDPF and predict the effective 
Table 1 The composition of herbs in CDPF

\begin{tabular}{|c|c|c|c|}
\hline Botanical name & English name & Chinese name & Abbreviation \\
\hline Herba Ephedrae & Ephedra & Ma Huang & $\mathrm{MH}$ \\
\hline Semen Armeniacae Amarum & Bitter apricot seed & Ku Xing Ren & KXR \\
\hline Gypsum Fibrosum & Gypsum & Shi Gao & SG \\
\hline Rhizoma et Radix Notopterygii & Incised notopterygium rhizome and root & Qiang Huo & $\mathrm{QH}$ \\
\hline Semen Descurainiae & Semen lepidii & Ting Li Zi & $\mathrm{TLZ}$ \\
\hline Rhizoma Dryopteris Crassirhizomae & Male fern rhizome & Guan Zhong & GZ \\
\hline Radix Cynanchi Paniculati & Paniculate swallowwort root & Xu Chang Qing & $X C Q$ \\
\hline HerbaPogostemonis & Cablin patchouli herb & Guang Huo Xiang & $\mathrm{GHX}$ \\
\hline Herba Eupatorii & Fortune eupatorium herb & Pei Lan & $P L$ \\
\hline Rhizoma Atractylodis & Atractylodes rhizome & Cang Zhu & $C Z$ \\
\hline Poria & Indian bread & Fu Ling & $\mathrm{FL}$ \\
\hline Rhizoma Atractylodis Macrocephalae & Largehead atractylodes rhizome & Bai Zhu & $B Z$ \\
\hline Cortex Magnoliae Officinalis & Officinal magnolia bark & Hou Po & $\mathrm{HP}$ \\
\hline Fructus Tsaoko & Fruit of caoguo & Cao Guo & $C G$ \\
\hline Lumbricus & Pheretima & Di Long & $\mathrm{DL}$ \\
\hline Fructus Crataegi & Charred hawthorn & Jiao Shan Zha & $J S Z$ \\
\hline Massa Medicata Fermentata & Fried medicated leaven & Jiao Shen Qu & JSQ \\
\hline Fructus Hordei Germinatus & Burnt malt & Jiao Mai Ya & JMY \\
\hline Semen Arecae & Arecaesementostum & Jiao Bing Lang & $J B L$ \\
\hline Rhizoma Zingiberis Recens & Fresh ginger & Sheng Jiang & SJ \\
\hline
\end{tabular}

targets of these active components. Consequently, we proposed potential mechanisms underlying the effects of CDPF in the treatment of COVID-19 at a molecular level, which might provide theoretical support for the wider application of CDPF in the fight against COVID-19.

\section{Methods}

\section{Collection of ingredients of CDPF and screening}

The components of herbs used in CDPF were retrieved from the Traditional Chinese Medicine Systems Pharmacology (TCMSP) database (http://tcmspw.com/tcmsp .php) and Traditional Chinese Medicines Integrated Database (TCMID) (http://www.megabionet.org/tcmid /) [25], and related references. The candidate ingredients from the TCMSP were retained only if their oral bioavailability $(\mathrm{OB}) \geq 30 \%$ and if their drug likeness $(\mathrm{DL}) \geq 0.18$ [26]. Candidate ingredients without potential target information were excluded. The properties of ingredients collected through the TCMID and literature reviews were retrieved from the Swiss ADME database (http://www.swissadme.ch/). The screening criterion for gastrointestinal GI absorption was set as high, and DL is satisfied with both "yes" at the same time [27]. The structures and SMILES format files of the compounds were obtained from the PubChem (https://pubchem.ncbi.nlm. nih.gov/) database [28].

\section{Construction of targets related to the identified compounds}

To obtain the target of each identified compound, putative targets were predicted from three databases: the TCMSP, similarity ensemble approach (SEA) (http:// sea.bkslab.org) [29], and STITCH (http://stitch.embl. $\mathrm{de} /$ ) database [30]. The SMILES format of the identified compounds was uploaded to the STITCH and SEA databases with the "Homo sapiens" setting. Afterward, the target proteins corresponding to the compounds screened from the three target databases were standardized in the UniProt (https://www.uniprot.org) database, with the properties set to "reviewed" and "human" [31]. Finally, the targets from the three databases were merged, and the duplicated targets were removed. A Venn Diagram (http://bioinformatics.psb.ugent.be/ webtools/Venn/) was used to filter the repeated targets among active components of herbs and to construct the herbs-ingredients-targets network using Cytoscape v.3.2.1 software.

\section{Target dataset for COVID-19}

COVID-19-related targets were retrieved from the Human Gene Database (GeneCards, https://www.genec ards.org/) [32] with the keyword "novel coronavirus pneumonia." The targets were also sent to the UniProt Database for normalization. 


\section{Protein-protein interaction}

To clarify the interaction between CDPF-related targets and COVID-19 targets, we screened for overlaps between CDPF-related targets and COVID-19 targetrelated targets. Then, we uploaded the list of overlapping proteins to the Search Tool for the Retrieval of Interacting Genes/Proteins database (STRING) v.11.0 (https:// string-db.org/) for PPI analysis [33], with the species limited to "Homo sapiens" and the confidence score cut-off set at 0.4 , and the rest of the settings were default. Finally, the final PPIs network was established.

\section{Network construction and analysis}

We constructed a PPI network for active ingredients of CDPF and putative COVID-19-related targets of these ingredients based on STRING, and applied Cytoscape v.3.2.1 software to visualize and analyse the interaction network [34]. To study further into the network, the candidates were screened with clustering. Clustering with the Overlapping Neighborhood Expansion (ClusterONE) plug-in of the Cytoscape software was employed to mine the highly interacting gene modules [35], with the minimum size parameter set to 3 . The cytoHubba plug-in of the Cytoscape software was used to obtain the top-10 genes, which fetches the shortest path among a group of nodes, based on a mixed character calculation (MCC) score [36].

\section{Gene ontology-enrichment and pathway-enrichment analyses}

The candidate genes screened by ClusterONE were further analysed to understand their gene ontology (GO) function, by using the Cytoscape plug-in ClueGO to annotate and visualise the interrelations of terms and functional groups in biological networks. The relevant biological processes (BP), molecular functions (MF), cellular components (CC), and Kyoto Encyclopedia of Genes and Genomes (KEGG) pathway-enrichment analysis were selected, with a threshold value of $p<0.05$ and a kappa score $\geq 0.4$.

\section{Molecular docking}

Through the above-mentioned cytoHubba analysis, the hub genes for the treatment of COVID-19 were obtained. The top hub gene and other key genes with the more connected active component in herbs were linked by molecular docking. The structural formula (SDF format) of the compounds were downloaded from the PubChem database and converted to PDB format with Open babel v.2.4.1 [37] from the RCSB Protein Data Bank (PDB, https ://www.rcsb.org/) to obtain the crystal structure of the core target [38]. The targets were processed by removing water, adding hydrogen, optimising amino acids, and selecting the magnetic field, and the pdbqt format was saved as a pair acceptor. Atomic charges and assigned atom types were added to compounds in the PDB format, and the pdbqt format was saved as a docked ligand. The active site for molecular docking was determined and size was set. Finally, Autodock Vina v.1.1.2 was run to perform molecular docking [39]. PyMOL v.2.3 software [40], and Molecular Operating Environment v.2.2 (MOE) software [41] were used to visualize the docking results, and based on the binding conformations of the docking results of each compound, the docking results with lower binding energy and better conformation were selected.

\section{Results}

Active components screening for CDPF

In this study, components of 20 herbal medicines in CDPF were collected, of which Ma Huang (MH, Herba Ephedrae), $\mathrm{Ku}$ Xing Ren (KXR, Semen Armeniacae Amarum), Qiang Huo (QH, Rhizoma et Radix Notopterygii), Ting Li Zi (TLZ, Semen Descurainiae), Guan Zhong (GZ, Rhizoma Dryopteris Crassirhizomae), Xu Chang Qing (XCQ, Radix Cynanchi Paniculati), Guang Huo Xiang (GHX, Herba Pogostemonis), Pei Lan (PL, Herba Eupatorii), Cang Zhu (CZ, Rhizoma Atractylodis), Fu Ling (FL, Poria), Bai Zhu (BZ, Rhizoma Atractylodis Macrocephalae), and Hou Po (HP, Cortex Magnoliae Officinalis) were identified from the TCMSP database; Shi Gao (SG, Gypsum Fibrosum), Di Long (DL, Lumbricus), Jiao Bing Lang (JBL, Semen Arecae), Cao Guo (CG, Fructus Tsaoko), and Sheng Jiang (SJ, Rhizoma Zingiberis Recens) were retrieved from the TCMID database; and Jiao Shan Zha (JSZ, Fructus Crataegi) [42-44], Jiao Shen Qu (JSQ, Massa Medicata Fermentata) [44], and Jiao Mai Ya (JMY, Fructus Hordei Germinatus) [44-46] were obtained by literature mining. Next, according to the screening criteria of the ADME, including the OB (or GI absorption) and DL, 193 active ingredients of CDPF were retrieved after duplicated targets were eliminated. Details of component information are provided in the Additional file 1: Table S1.

\section{Target fishing for active CDPF components and construction of the component-target network}

The TCMSP, SEA, and STITCH databases were searched for candidate targets of active CDPF ingredients. After fishing for targets, 1172 targets were found for $\mathrm{MH}, 488$ targets were found for KXR, 276 targets were found for $\mathrm{QH}, 647$ targets were found for TLZ, 165 targets were found for GZ, 25 targets were found for XCQ, 397 targets were found for GHX, 211 targets were found for PL, 276 targets were found for $\mathrm{CZ}, 77$ targets were found for FL, 73 targets were found for BZ, 43 targets were found for HP, 371 targets were found for 
CG, 165 targets were found for SJ, 6 targets were found for DL, 42 targets were found for JBL, 494 targets were found for JMY, 1023 targets were found for JSZ, and 85 targets were found for JSQ. Details of target information are provided in the Additional file 2: Table S2.

The main herbs of CDPF had synergistic effects with each other as exhibited by a Venn diagram. BZ, CG, CZ, FL, GZ, HP, GHX, JMY, JSZ, KXR, MH, PL, QH, SJ, TLZ, and XCQ shared three targets, CG, CZ, GZ, GHX, JMY, JSZ, KXR, MH, PL, QH, and TLZ shared seven targets, BZ, CG, CZ, FL, KXR, MH, PL, QH, SJ, and TLZ shared 12 targets, and CG, GHX, JMY, JSZ, $\mathrm{MH}$, and TLZ shared up to 62 targets, etc. Although there were too many different lists to be captured in a single diagram, the details of the Venn diagram are provided in text form in the Additional file 3: Table S3.

Overall, 949 candidate targets of active CDPF components were identified after removing duplication, and the herbs-ingredients-targets interaction network was consequently constructed using Cytoscape v.3.2.1 software. In order to simplify the network, the nodes above the average degree were selected to build the high connections of "herbs - ingredients - targets" network (Fig. 1). The network containing all the nodes of 949 candidate targets of active CDPF components was shown in Additional file 4: Fig. S1.

\section{Potential COVID-19 targets of CDPF}

For disease target identification, 259 target genes that occur in COVID-19 were identified from the GeneCards database (Additional file 5: Table S4). Seventy-one target genes overlapped between CDPF and COVID-19 and were selected as potential targets for further analysis (Table 2).

\section{PPI network analysis}

The STRING database was used to acquire PPI relationships of potential protein targets of CDPF as related to the treatment of COVID-19. By using these targets, the network of PPI relationships was shown to contain 71 nodes (representing active proteins) and 1006 edges (representing the interaction between the active proteins and proteins), with an average node degree of 28.3 and a PPIenrichment $p$ value of $<1.0 \mathrm{e}-16$.

In the PPI network, constructed with the Cytoscape software using parameters such as a minimum required interaction score $>0.4$ ) (Fig. 2a), the most significant module (Density $=0.438$, Quality $=0.874, p<0.001$ ) containing 68 nodes was then recognized by ClusterONE (Fig. 2b).

Moreover, the top 10 targets ranked by the MCC method were identified as hub genes using the cytoHubba plug-in (Fig. 2c). These targets included interleukin-6 (IL6), tumour necrosis factor (TNF), interleukin-10 (IL10), mitogen-activated protein kinase 8 (MAPK8),

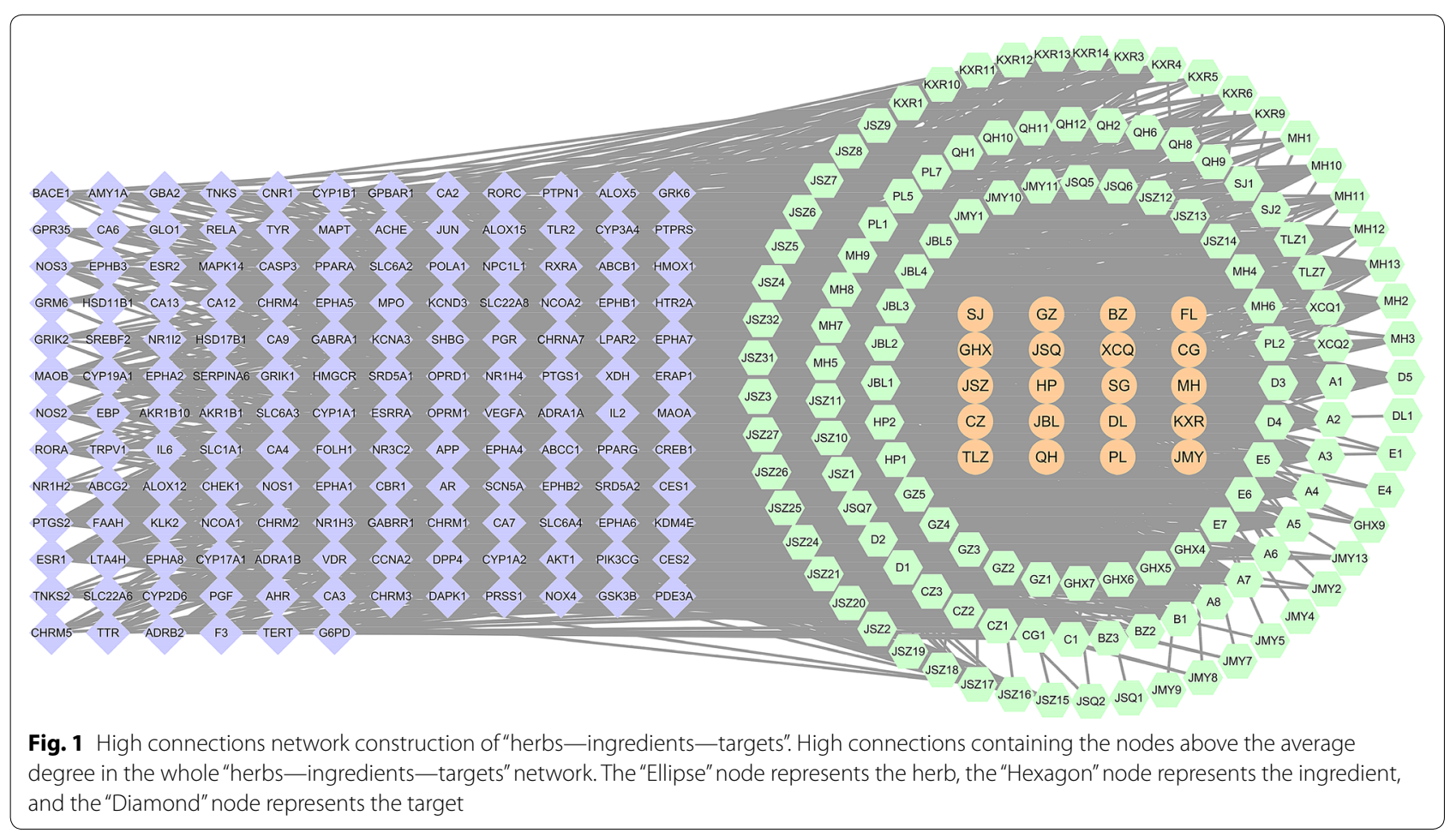


Table 2 Potential targets of CDPF against COVID-19

\begin{tabular}{|c|c|c|}
\hline Protein name & Gene symbol & Uniprot ID \\
\hline Prostaglandin G/H synthase 1 & PTGS1 & P23219 \\
\hline Prostaglandin G/H synthase 2 & PTGS2 & P35354 \\
\hline Mothers against decapentaplegic homolog 3 & SMAD3 & P84022 \\
\hline Heme oxygenase 1 & HMOX1 & P09601 \\
\hline Granulocyte-macrophage colony-stimulating factor & CSF2 & P04141 \\
\hline Nitric oxide synthase, inducible & NOS2 & P35228 \\
\hline Peroxisome proliferator activated receptor gamma & PPARG & P37231 \\
\hline Phosphatidylinositol-4,5-bisphosphate 3-kinase catalytic subunit, gamma isoform & PIK3CG & P48736 \\
\hline Dipeptidyl peptidase IV & DPP4 & P27487 \\
\hline Nitric-oxide synthase, endothelial & NOS3 & P29474 \\
\hline Transcription factor p65 & RELA & Q04206 \\
\hline Apoptosis regulator $\mathrm{BCl}-2$ & $\mathrm{BCL} 2$ & P10415 \\
\hline Apoptosis regulator BAX & BAX & Q07812 \\
\hline Tumor necrosis factor & TNF & P01375 \\
\hline Caspase-3 & CASP3 & P42574 \\
\hline Mitogen-activated protein kinase 8 & MAPK8 & P45983 \\
\hline Signal transducer and activator of transcription 1-alpha/beta & STAT1 & P42224 \\
\hline Intercellular adhesion molecule 1 & ICAM1 & P05362 \\
\hline Transthyretin & TTR & P02766 \\
\hline Coagulation factor $\mathrm{Xa}$ & F10 & P00742 \\
\hline Epidermal growth factor receptor & EGFR & P00533 \\
\hline Bcl-2-like protein 1 & BCL2L1 & Q07817 \\
\hline Proto-oncogene c-Fos & FOS & P01100 \\
\hline Mitogen-activated protein kinase 1 & MAPK1 & P28482 \\
\hline Interleukin-10 & IL10 & P22301 \\
\hline Retinoblastoma-associated protein & RB1 & P06400 \\
\hline Interleukin-6 & IL6 & P05231 \\
\hline Cellular tumor antigen p53 & TP53 & P04637 \\
\hline Caspase-8 & CASP8 & Q14790 \\
\hline Superoxide dismutase [Cu-Zn] & SOD1 & P00441 \\
\hline Protein kinase $C$ alpha type & PRKCA & P17252 \\
\hline Interleukin-1 beta & IL1B & P01584 \\
\hline $\mathrm{C}-\mathrm{C}$ motif chemokine 2 & CCL2 & P13500 \\
\hline Interleukin-8 & CXCL8 & P10145 \\
\hline Protein kinase $C$ beta type & PRKCB & P05771 \\
\hline Heat shock protein beta-1 & HSPB1 & P04792 \\
\hline Interleukin-2 & IL2 & P60568 \\
\hline Plasminogen activator inhibitor 1 & SERPINE1 & P05121 \\
\hline Interferon gamma & IFNG & P01579 \\
\hline Interleukin-1 alpha & IL1A & P01583 \\
\hline Poly [ADP-ribose] polymerase 1 & PARP1 & P09874 \\
\hline C-X-C motif chemokine 11 & CXCL11 & 014625 \\
\hline C-X-C motif chemokine 2 & CXCL2 & P19875 \\
\hline C-X-C motif chemokine 10 & CXCL10 & P02778 \\
\hline CD40 ligand & CD40LG & P29965 \\
\hline Phosphatidylinositol 3-kinase regulatory subunit alpha & PIK3R1 & P27986 \\
\hline Induced myeloid leukemia cell differentiation protein Mcl-1 & MCL1 & Q07820 \\
\hline Interleukin-4 & IL4 & P05112 \\
\hline Cyclic AMP-responsive element-binding protein 1 & CREB1 & P16220 \\
\hline
\end{tabular}


Table 2 (continued)

\begin{tabular}{|c|c|c|}
\hline Protein name & Gene symbol & Uniprot ID \\
\hline Glucose-6-phosphate 1-dehydrogenase & G6PD & P11413 \\
\hline Catalase & CAT & P04040 \\
\hline Cytosolic phospholipase A2 & PLA2G4A & P47712 \\
\hline Protein kinase C epsilon type & PRKCE & Q02156 \\
\hline Mitogen-activated protein kinase 3 & MAPK3 & P27361 \\
\hline Calmodulin-1 & CALM1 & P0DP23 \\
\hline T-cell surface glycoprotein CD4 & CD4 & P01730 \\
\hline Mitogen-activated protein kinase 14 & MAPK14 & Q16539 \\
\hline Nuclear factor NF-kappa-B p105 subunit & NFKB1 & P19838 \\
\hline Angiotensin-converting enzyme & ACE & P12821 \\
\hline Cyclin-dependent kinase 4 & CDK4 & P11802 \\
\hline CD81 antigen & CD81 & P60033 \\
\hline Eukaryotic translation initiation factor 2 subunit 1 & EIF2S1 & P05198 \\
\hline Growth factor receptor-bound protein 2 & GRB2 & P62993 \\
\hline Apolipoprotein E & APOE & P02649 \\
\hline C-C chemokine receptor type 3 & CCR3 & P51677 \\
\hline Angiotensin-converting enzyme 2 & ACE2 & Q9BYF1 \\
\hline Aminopeptidase N & ANPEP & P15144 \\
\hline Serine/threonine-protein kinase/endoribonuclease IRE1 & ERN1 & O75460 \\
\hline Cyclic AMP-dependent transcription factor ATF-2 & ATF2 & P15336 \\
\hline Cathepsin B & CTSB & P07858 \\
\hline Peptidyl-prolyl cis-trans isomerase A & PPIA & P62937 \\
\hline
\end{tabular}

mitogen-activated protein kinase $3(M A P K 3)$, interleukin-8 (CXCL8), caspase-3 (CASP3), prostaglandin $\mathrm{G} / \mathrm{H}$ synthase 2 (PTGS2), cellular tumour antigen p53 (TP53), and mitogen-activated protein kinase 1 (MAPK1).

\section{GO-enrichment analysis}

To determine the biological features of the candidate targets screened by ClusterONE, GO analysis was accomplished by the Cytoscape plug-in ClueGO. Based on filter conditions of $p<0.05$ and kappa score $\geq 0.4$, $\mathrm{GO}$ function-enrichment analysis resulted in 466 items, of which BP accounted for 446, CC for 2, and MF for 18 items. BP analysis revealed that the candidate targets were markedly enriched for cellular response to biotic stimulus, inflammatory response, regulation of inflammatory response, reactive oxygen species metabolic process, positive regulation of response to external stimulus, cellular response to external stimulus, cytokine production, regulation of sequence-specific DNA binding transcription factor activity, regulation of chemokine production, reactive oxygen species biosynthetic process, regulation of leukocyte migration, leukocyte homeostasis, B cell proliferation, $\mathrm{T}$ cell migration, lymphocyte activation involved in immune response, regulation of nitric oxide biosynthetic process, and response to reactive oxygen species, positive regulation of hemopoiesis, regulation of vasculature development, platelet activation, regulation of blood vessel diameter, positive regulation of cytokine production, regulation of cytokine biosynthetic process, response to extracellular stimulus, response to drug, response to toxic substance, regulation of chemokine biosynthetic process, regulation of production of molecular mediator of immune response, acute inflammatory response, regulation of acute inflammatory response, regulation of immunoglobulin production, receptor-mediated virion attachment to host cell, cellular oxidant detoxification, defense response to protozoan, positive regulation of homeostatic process, and other (Additional file 6: Table S5-1). Here top 20 GO terms of BP were listed by bubble chart according to "term $p$-value corrected with Bonferroni step down". The CC analysis showed that these candidate genes were enriched in membrane rafts and plasma membrane rafts (Fig. 3b, Additional file 6: Table S5-2). Changes in the MF of the targets were mainly significantly enriched for cytokine receptor binding, phosphatase binding, BH3 domain binding, activating transcription factor binding, chemokine activity, tumour necrosis factor receptor superfamily binding, nuclear hormone receptor binding, R-SMAD binding, and peroxidase activity (Fig. 3c, Additional file 6: Table S5-3). 


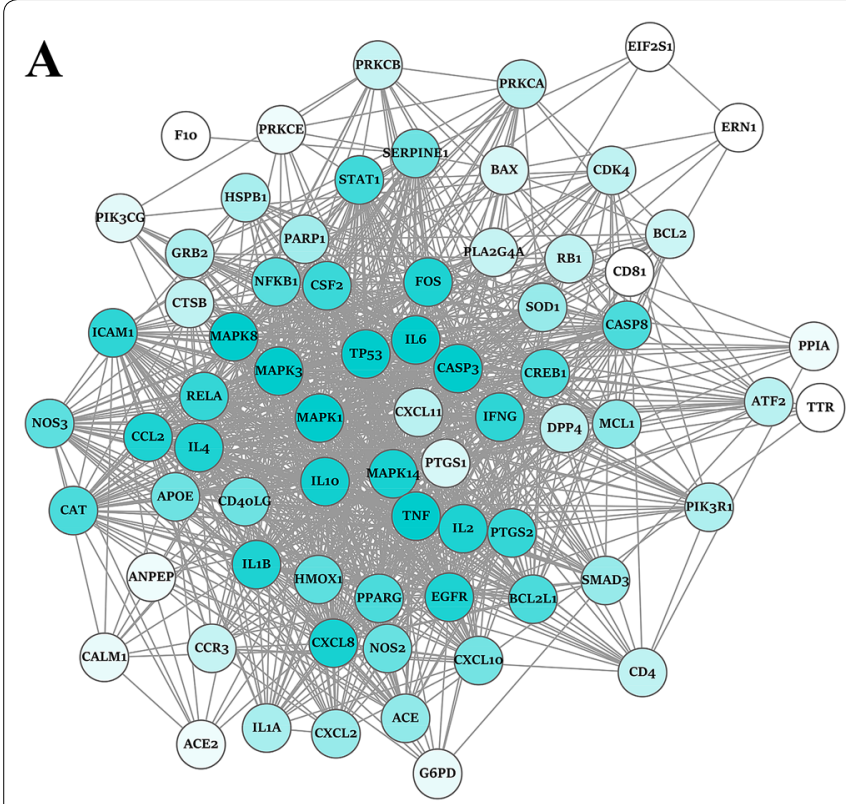

B

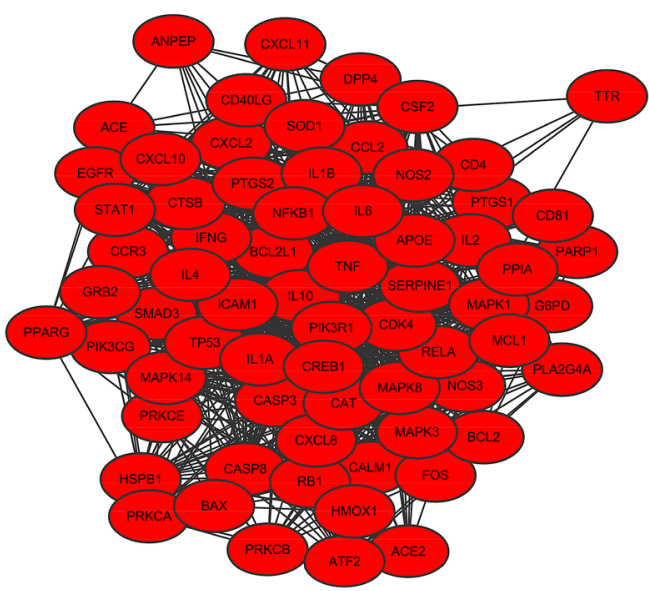

$\mathbf{C}$
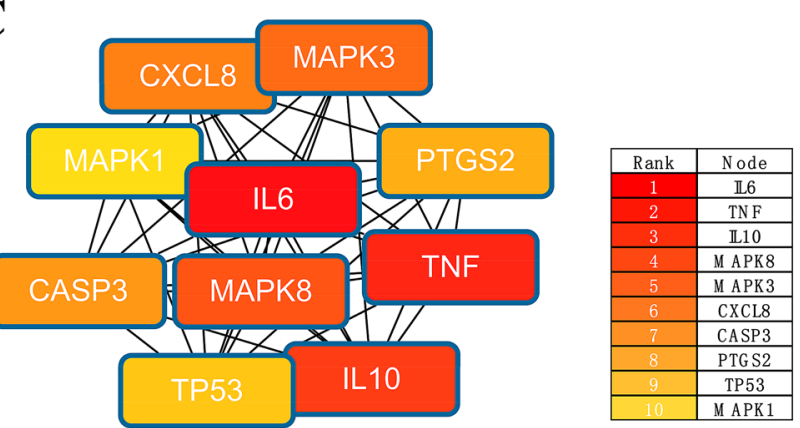

Fig. 2 Protein-protein interaction (PPI) Analysis. A. PPI networks of all candidate targets of CDPF for the treatment of COVID-19 from STRING 11.0 and was exhibited by Cytoscape plug-in. Nodes represent proteins (Low values to bright colors depend on the degree). Edges represent proteinprotein associations. B. The most significant module identified by ClusterONE plug-in (Density $=0.438$, Quality $=0.874, p<0.001$ ). C. The top 10 targets (hub targets) in the PPI network ranked by maximal clique centrality (MCC) using cytoHubba plug-in

\section{KEGG pathway analysis}

To explore the potential mechanism related to these candidate targets identified by ClusterONE, KEGG pathway analysis was performed. Based on filter conditions of $p<0.05$ and kappa score $\geq 0.4$, KEGG pathway analysis returned 137 items, including TNF signaling pathway, MAPK signaling pathway, Fc epsilon RI signaling pathway, toxoplasmosis, leishmaniasis, estrogen signaling pathway, natural killer cell mediated cytotoxicity, chagas disease, osteoclast differentiation, longevity regulating pathway, influenza A, sphingolipid signaling pathway, inflammatory bowel disease (IBD), apoptosis, hepatitis B, HTLV-I infection, pertussis, antigen processing and presentation, renin-angiotensin system, and viral myocarditis, AGE-RAGE signaling pathway in diabetic complications, and so on (Fig. 4, Additional file 7: Table S6). These items revealed that the potential pathways affected by CDPF mainly involved improving immunity, anti-inflammatory effects, fighting against viruses and other pathogens.

\section{Molecular docking}

Molecular simulation was used to verify the binding ability of CDPF bioactive components to the key targets and explore their accurate binding modes. In this respect, the top hub target, IL6 (PDB ID: 1IL6), was selected, using quercetin and luteolin as its ligands; and as a typical receptor for SARS-CoV-2 entry into host cells, ACE2 (PDB ID: 3D0G) was chosen, using L-tyrosine and L-phenylalanine as its ligands. In this analysis, the value of the vina score indicates the binding activity between a compound and a protein. The more negative the vina score, the more stably the compound binds to the protein. As shown in Fig. 5, IL6 demonstrates strong binding to quercetin (Score $=-7.3$ ) and luteolin (Score $=-7.2)$; similarly, ACE2 binds strongly to L-tyrosine (Score $=-6.5$ ) and L-phenylalanine 


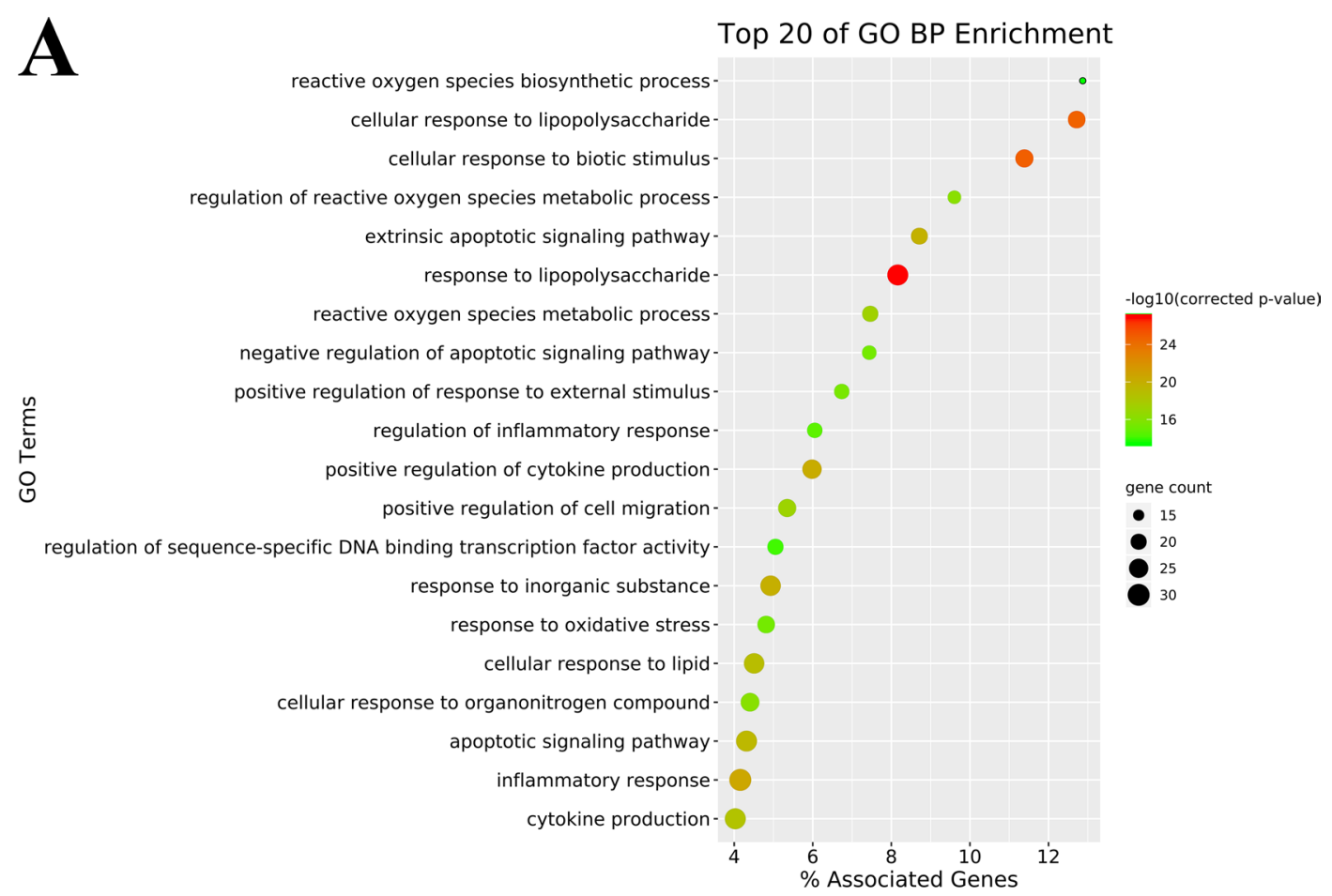

B
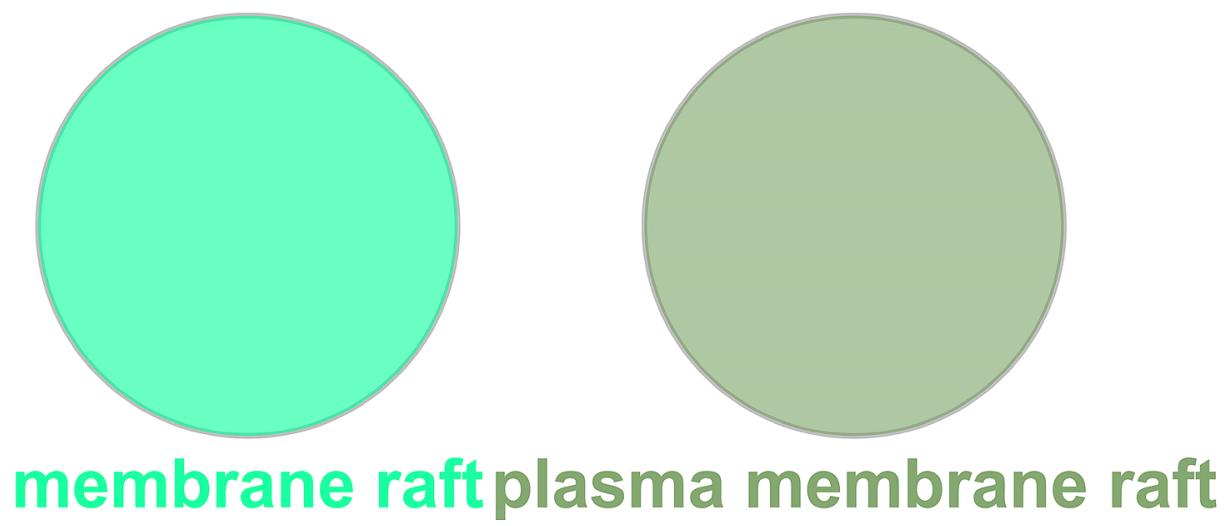

Fig. 3 GO enrichment analysis of the potential targets of CDPF against COVID-19 by ClueGO plug-in. a Top 20 GO terms of biological process (BP) were listed by bubble chart according to "term $p$-value corrected with Bonferroni step down"; GO terms, including b cellular component (CC) terms, c molecular function (MF) terms, are represented as nodes, and size of the node represents significance. Only the most significant terms in the group have been labelled

(Score $=-6.3)$. In terms of interaction points, IL6 mainly interacted with quercetin via amino acid residues Asn62, Leu166, Arg169, Glu173, Leu63, Leu65, Pro66, Phe174, and Met68, and with luteolin via residues Leu166, Ser170, Glu173, Phe174, Phe75, Asn62, Leu63, Leu65, Pro66, and Met68. ACE2 mainly interacted with L-tyrosine via amino acid residues Ala413, Phe438, Thr434, Asn437, Ile291, Asn290, and Pro289; and with L-phenylalanine via residues
Ala413, Phe438, Glu435, Glu430, Ile291, Phe428, and Thr434.

\section{Discussion}

TCM prescriptions are rich in resource-based chemical components, with complex chemical structures, different targets, and diverse action pathways, which work together to exert their unique clinical efficacy. In order to explain 


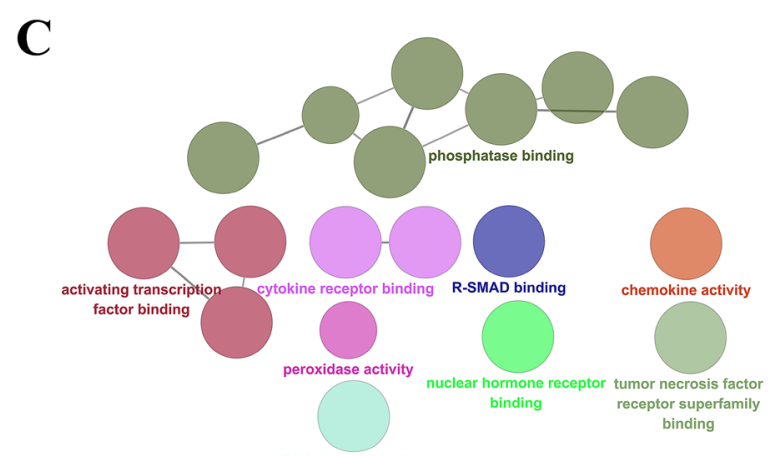

Fig. 3 continued

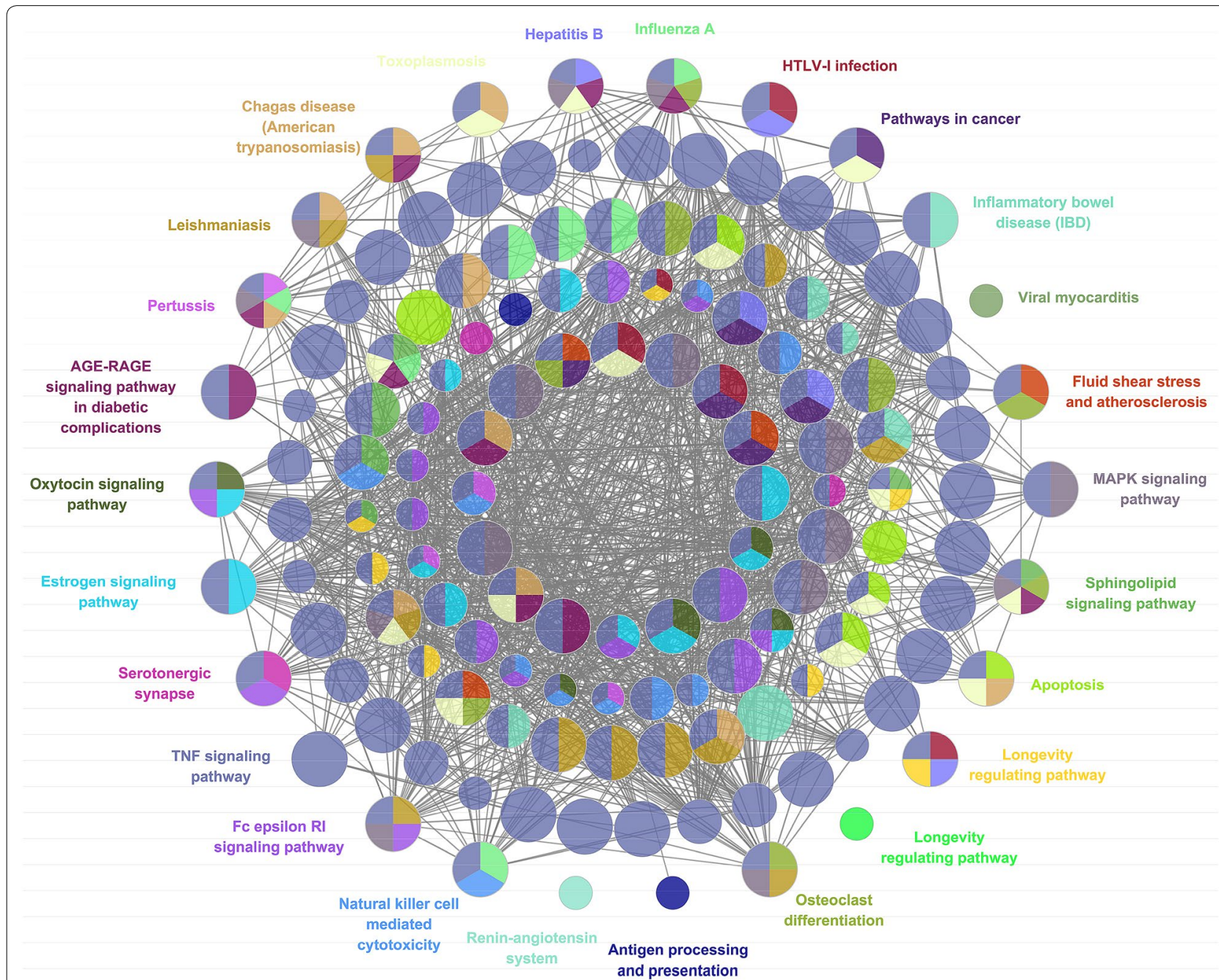

Fig. 4 KEGG pathway analysis of the potential targets of CDPF against COVID-19 by ClueGO plug-in. KEGG terms are represented as nodes, only the most significant terms in the group have been labelled, and small labels are hidden 


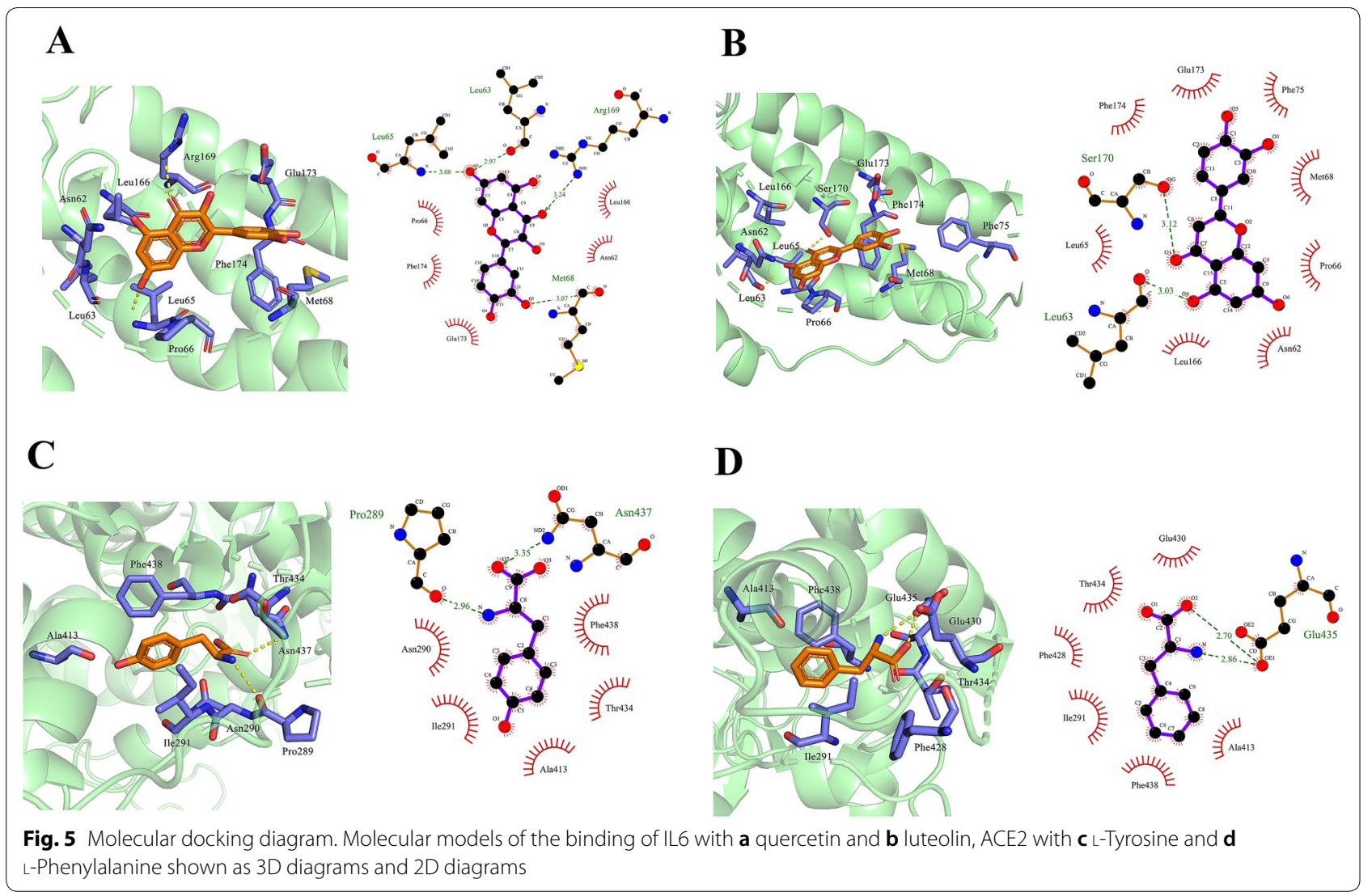

the therapeutic basis of CDPF against COVID-19 scientifically, this study revealed the active ingredients and potential molecular mechanism by which CDPF treatment is effective against COVID-19, and provides a reference basis for the wider application and further mechanistic investigations of CDPF in the fight against COVID-19.

First, we considered the compound's feasibility for use as a drug, based on the database of TCMSP and TCMID and related references, combining the OB (or GI absorption) and DL values of the compound. Consequently, 193 active compounds of CDPF were assessed and 949 candidate targets of these active compounds were screened through drug target-prediction databases. Venn plots of these candidate targets showed that several herbs shared common targets; for example, the CG, GHX, JMY, JSZ, $\mathrm{MH}$, and TLZ shared up to 62 targets, illustrating the synergy between herbs. We thus constructed an herbsingredients-targets network, which intuitively reflected the characteristics of CDPF, which has multiple components and targets.

We retrieved 259 candidate COVID-19 targets from the GeneCards database. Through target mapping, we found 71 targets in common between CDPF active componenttargets and these disease targets, which were considered potential targets for CDPF in the treatment of COVID-19.
To identify functional connections among these common targets, PPIs were predicted using STRING. We carried out module analysis on a PPI network via the ClusterONE plug-in in Cytoscape; modularization is an important step, as it helps to reduce the noise of the data. By modularization, the most significant cluster (Density $=0.438$, Quality $=0.874, \mathrm{p}<0.001)$ was obtained, which contained 68 seed proteins. We subsequently performed GO and KEGG analyses of these seed proteins.

Using ClueGo enrichment analysis, significant biological processes related to the anti-COVID-19 effects of CDPF were identified. These mainly focused on four areas: (1) Cellular responses to external stimuli, such as cellular response to external stimulus, positive regulation of response to external stimulus, response to extracellular stimulus, cellular response to biotic stimulus, and even receptor-mediated virion attachment to host cell. (2) Regulation of blood production and circulation, such as regulation of vasculature development, platelet activation, positive regulation of hemopoiesis, and regulation of blood vessel diameter. SARS-CoV-2 may cause blood clotting and trigger the risk of stroke [47-49]; the above biological processes may be effective against the occurrence of blood clotting. (3) Free radical regulation, such as reactive oxygen species metabolic process, reactive oxygen species 
biosynthetic process, regulation of nitric oxide biosynthetic process, and response to reactive oxygen species. Some studies have indicated that high levels of reactive oxygen species and other free radicals are generated after virus invasion, thereby inducing damage to the organism [5052]. These biological functions involve the regulation of free radical production and metabolism. (4) Immune regulation and anti-inflammatory effects, such as cytokine production, regulation of cytokine biosynthetic process, regulation of inflammatory response, regulation of leukocyte migration, regulation of cytokine biosynthetic process, regulation of production of molecular mediator of immune response, regulation of leukocyte migration, leukocyte homeostasis, $\mathrm{B}$ cell proliferation, $\mathrm{T}$ cell migration, lymphocyte activation involved in immune response, regulation of chemokine production, regulation of acute inflammatory response, regulation of immunoglobulin production, positive regulation of lymphocyte proliferation. In order to fight against a viral invasion, the organism stimulates a series of immune responses. Leukocytes quickly migrate to the site of the virus invasion to surround and phagocytize the virus [53, 54]. As the virus continues to replicate, B lymphocytes are activated by antigens, forming plasma cells, and producing immunoglobulins (antibodies), and then antigen-antibody binding participates in the humoral immune response through the blood and body fluids [55, 56]. Moreover, a large number of cytokines are released by immune cells to play an anti-viral role; these include ILs, interferons, TNFs, colony stimulating factors, chemokines, and growth factors [57-59]. However, while the body produces an immune response to eliminate the virus, the cytokines secreted by the immune cells activate further immune cells, which in turn produce more cytokines, and induce a "cytokine storm." Eventually, the immune system begins to attack the normal cells of the host $[60,61]$. This reflects two-way regulation: on the one hand, the body can quickly produce an immune response to play a role in eliminating the virus; on the other hand, it can regulate the production and secretion of cytokines to avoid the occurrence of a cytokine storm, which would cause damage to the organism.

KEGG pathway analysis showed that CDPF mainly regulates disease pathways induced by viruses, such as hepatitis B, influenza A, HTLV-I infection, and viral myocarditis. Additionally, CDPF regulates pathways of diseases caused by external organisms, such as bacteria or worms, including pertussis, leishmaniasis, chagas disease, and toxoplasmosis, etc. Immune and inflammatory pathways, such as antigen processing and presentation, natural killer cell mediated cytotoxicity [62], Fc epsilon RI signaling pathway, associating with the secretion of cytokines, such as TNF- $\alpha$, contributing to inflammatory responses [63], TNF signaling pathway [64], and MAPK signaling pathway [65], and inflammatory disease-related pathways, such as IBD, are also involved. Sphingolipid signaling pathway utilizes second messenger functions involved in a variety of cellular signalling pathways; sphingolipids appear to be mediators of inflammation and are novel therapeutic targets in inflammatory disease [66]. CDPF also targeted the AGERAGE signaling pathway, which is involved in diabetic complications. Diabetes mellitus is a major comorbidity complicating COVID-19, and the association between glycaemic control and prognosis in patients with comorbid COVID-19 and diabetes has been reported [67]. ACE2, a gene involved in the renin-angiotensin system, has been shown to be a therapeutic target in COVID-19, as SARSCoV-2 uses ACE2 as a receptor to enter host cells $[68,69]$. In addition, pathways related to apoptosis, longevity, and estrogen signalling are also regulated by CDPF.

Moreover, in the PPI network, the top 10 targets (IL6, TNF, IL10, MAPK8, MAPK3, CXCL8, CASP3, PTGS2, TP53, and MAPK1) were regarded as hub genes that may play important roles in the treatment of COVID-19 by CDPF and are involved in the regulation of immunity and inflammation. For example, TNF has immune regulatory, proinflammatory [70], and anti-viral functions [71], MAPK8 modulates lymphocyte homeostasis [72], IL10 is generally considered to be an anti-inflammatory cytokine $[73,74]$, but production of IL-10 has also been shown to be detrimental during high-dose primary influenza challenge [75]. CXCL8 increases recruitment of principal human neutrophils and is a major inflammatory mediator [76], while PTGS2 is also an inflammatory marker [77]. The most notable factor was IL6, which plays a key role in the cytokine storm [78, 79], and is used as a clinical early warning index in the diagnosis and treatment of COVID19 [80, 81]. IL6 plays a central role in the acute inflammatory response, and a long duration of its release can also be used to assess the severity of infection and judge prognosis [82, 83]. Dynamic observation of IL-6 levels can assist in understanding the progression of infectious diseases and the response to treatment $[84,85]$.

We then performed docking studies for IL6, using the critical ingredients quercetin and luteolin as ligands, and for ACE2, the receptor by which SARS-CoV-2 typically enters host cells, with its ligands, L-tyrosine and L-phenylalanine. Molecular docking allows assessment of whether it is thermodynamically possible for the ligand and protein to bind. The binding energies of these docking results further helped to refine the targets of CDPF. Finally, the vina scores of the active compounds with the key targets were all negative and less than -6 , and their interaction points were revealed, and demonstrated that quercetin and luteolin, and L-tyrosine and L-phenylalanine had good binding activities to IL6 and ACE2, respectively. 


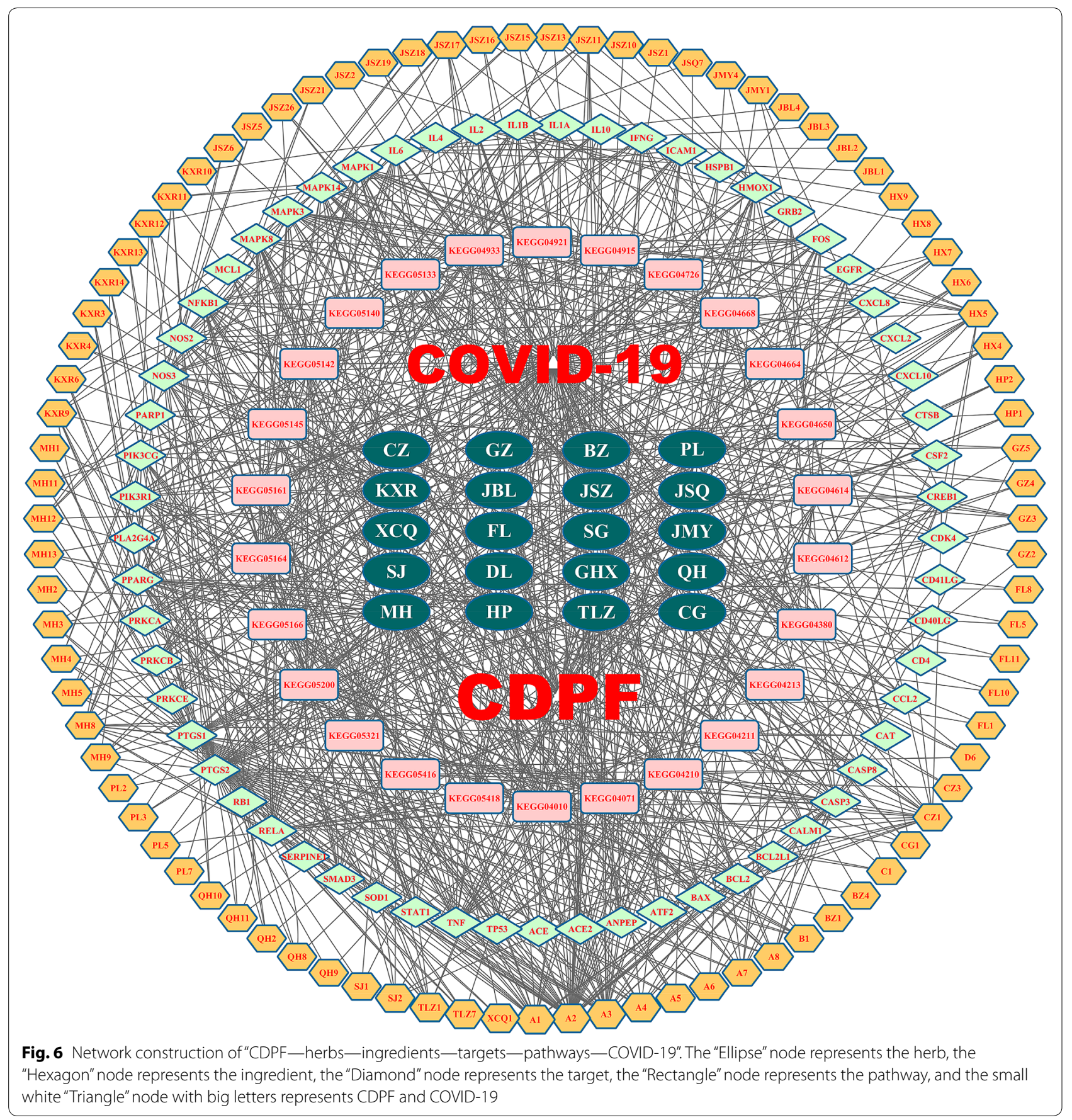

\section{Conclusions}

In this study, we systematically analysed the potential mechanism by which CDPF is effective in the treatment of COVID-19, based on network pharmacology. A CDPFherbs-ingredients-targets-pathways-COVID-19 network was constructed (Fig. 6). The results demonstrated a synergistic effect between herbs and illustrated that CDPF could play pharmacological roles in the treatment of COVID-19 through multi component-multi targetmulti pathway effects at the molecular level, mainly involving anti-viral, immune-regulatory, and anti-inflammatory actions. These findings may offer a reference basis for further investigations of the mechanism by which CDPF exerts effects against COVID-19. 


\section{Supplementary information}

Supplementary information accompanies this paper at https://doi. org/10.1186/s13020-020-00360-8.

Additional file 1: Table S1. The main active Components in CDPF.

Additional file 2: Table S2. Candidate targets of active ingredients in the CDPF.

Additional file 3: Table S3. The text results details of the Venn diagram.

Additional file 4: Fig. S1. Network of "herbs-ingredients-targets". The "Ellipse" node represents the herb, the "Hexagon" node represents the ingredient, and the "Diamond" node represents the target.

Additional file 5: Table S4. Candidate targets of COVID-19.

Additional file 6: Table S5. 1: Node attribute information of GO analysisbiological process (BP). 2: Node attribute information of $\mathrm{GO}$ analysiscellular component (CC). 3: Node attribute information of $\mathrm{GO}$ analysismolecular function (MF).

Additional file 7: Table S6. Node attribute information of KEGG analysis.

\section{Abbreviations}

TCM: Traditional Chinese medicine; CDPF: Cold-Damp Plague Formula; COVID19: Coronavirus disease 2019; SARS-CoV-2: Severe acute respiratory syndrome coronavirus 2; NCP: Novel coronavirus pneumonia; WHO: World Health Organization; TCMSP: Traditional Chinese Medicine Systems Pharmacology; TCMID: Traditional Chinese Medicines Integrated Database; OB: Oral bioavailability; DL: Drug likeness; SEA: Similarity ensemble approach; PPI: Protein-protein interaction; STRING: Search Tool for the Retrieval of Interacting Genes/Proteins database; ClusterONE: Clustering with Overlapping Neighborhood Expansion; MCC: Mixed character calculation; GO: Gene Ontology; BP: Biological processes; MF: Molecular functions; CC: Cellular components; KEGG: Kyoto Encyclopedia of Genes and Genomes; PDB: Protein Data Bank.

\section{Acknowledgements}

Not applicable.

\section{Authors' contributions}

$X-L T, L-H Z$, and $L H$ conceived and designed the research methods. $L H, X-X W$, $L-L Z, X-M W, H-Y Y$, and XM collected the data. $L H$ and $X-X W$ analysed the data. $\mathrm{LH}, \mathrm{X}-\mathrm{XW}$, and $\mathrm{Y}-\mathrm{JZ}$ wrote the original draft. $\mathrm{X}-\mathrm{LT}$ and $\mathrm{L}-\mathrm{HZ}$ reviewed and edited the manuscript. All authors read and approved the final manuscript.

\section{Funding}

This work was funded by the Special Project for Emergency of the Ministry of Science and Technology (2020YFC0845000).

\section{Availability of data and materials}

The datasets used and/or analysed during the current study are available from the corresponding author on reasonable request.

Ethics approval and consent to participate

Not applicable.

\section{Consent for publication}

Not applicable.

\section{Competing interests}

The authors declare no conflict of interest.

\section{Author details}

${ }^{1}$ Guang'anmen Hospital, China Academy of Chinese Medical Sciences, Beijing 100053, China. ${ }^{2}$ Beijing University of Chinese Medicine, Beijing 100029 , China. ${ }^{3}$ Gansu University of Chinese Medicine, Lanzhou 730000, China.

Received: 14 May 2020 Accepted: 24 July 2020

Published online: 30 July 2020

\section{References}

1. Singhal T. A review of coronavirus disease-2019 (COVID-19). Indian J Pediatr. 2020;87(4):281-6.

2. Liu X, Li G, Zhu H, Huang L, Liu Y, Ma C, Qin C. Beneficial effect of berberine on hepatic insulin resistance in diabetic hamsters possibly involves in SREBPs, LXRa and PPARa transcriptional programs. Endocr J. 2010;57(10):881-93.

3. Lee YS, Kim WS, Kim KH, Yoon MJ, Cho HJ, Shen Y, Ye JM, Lee CH, Oh WK, Kim CT, Hohnen-Behrens C, Gosby A, Kraegen EW, James DE, Kim JB. Berberine, a natural plant product, activates AMP-activated protein kinase with beneficial metabolic effects in diabetic and insulin-resistant states. Diabetes. 2006:55(8):2256-64.

4. Xi X, Han J, Zhang JZ. Stimulation of glucose transport by AMP-activated protein kinase via activation of p38 mitogen-activated protein kinase. The Journal of biological chemistry. 2001;276(44):41029-34.

5. Ma Y, Chen M, Guo Y, Liu J, Chen W, Guan M, Wang Y, Zhao X, Wang $X$, Li H, Meng L, Wen Y, Wang Y. Prevention and treatment of infectious diseases by traditional Chinese medicine: a commentary. APMIS. 2019;127(5):372-84.

6. Liu DH, Liang BZ, Huang LY, Fang YC, Zheng JH, Wang GB, Zhang SC, Lin WJ, Huangtan ZY, Cai QM. Clinical Observation on the Preventive Effect of Kangdu Bufei Decoction on Acute Severe Respiratory Syndrome. Chinese Journal of Integrated Traditional and Western Medicine. 2004;24(8):685-8.

7. Tong XL, Li AG, Zhang ZY, Duan J, Chen XG, Hua CJ, Zhao D, Xu Y, Shi XP, Li P, Tian X, Lin F, Cao YT, Lu J, Chang M, Wang YT. TCM treatment of infectious atypical pneumonia-a report of 16 cases. J Tradit Chin Med. 2004;24(4):266-9.

8. Duan ZP, Jia ZH, Zhang J, Liu S, Chen Y, Liang LC, Zhang CQ, Zhang Z, Sun Y, Zhang SQ, Wang YY, Wu YL. Natural herbal medicine Lianhuaqingwen capsule anti-influenza A (H1N1) trial: a randomized, double blind, positive controlled clinical trial. Chin Med J. 2011;124(18):2925-33.

9. Zhuang YD, Lai ZY, Chen YJ, Yan CH, Cai WM, Hong HZ, Guo SR. Treatment of one severe case of human infection with avian infl uenza A (H7N9) virus by integrated traditional Chinese and western medicine. China Journal of Traditional Chinese Medicine and Pharmacy. 2014;29(4):969-71.

10. Ding YW, Zeng $\sqcup$, Li RF, Chen QY, Zhou BX, Chen QL, Cheng PL, Wang YT, Zheng JP, Yang ZF, Zhang FX. The Chinese prescription lianhuaqingwen capsule exerts anti-influenza activity through the inhibition of viral propagation and impacts immune function. BMC Complementary and Alternative Medicine. 2017;17(1):130.

11. The State Council Information Office of the People's Republic of China. The press conference was held for the important role and effective drugs of COVID-19 in the prevention and treatment of traditional Chinese medicine by The State Council Information Office of the People's Republic of China. http://www.scio.gov.cn/xwfbh/xwbfbh/wqfbh/42311/42768 /index.htm (Accessed on 23 March 2020).

12. Zhou JY, Zhou SW. Effect of berberine on PPARalpha/delta/gamma expression in type 2 diabetic rat retinae. Yao xue xue bao Acta pharmaceutica Sinica. 2007;42(12):1243-9.

13. Yang R, Liu H, Bai C, Wang Y, Zhang X, Guo R, Wu S, Wang J, Leung E, Chang H, Li P, Liu T, Wang Y. Chemical composition and pharmacological mechanism of Qingfei Paidu Decoction and Ma Xing Shi Gan Decoction against Coronavirus Disease 2019 (COVID-19): in silico and experimental study. Pharmacol Res. 2020;157:104820.

14. Du H-Z, Hou X-Y, Miao Y-H, Huang B-S, Liu D-H. Traditional Chinese Medicine: an effective treatment for 2019 novel coronavirus pneumonia (NCP). Chin J Nat Med. 2020;18(3):206-10.

15. Kong $Q$, Wu Y, Gu Y, Lv Q, Qi F, Gong S, Chen X. Analysis of the molecular mechanism of Pudilan (PDL) treatment for COVID-19 by network pharmacology tools. Biomed Pharmacother. 2020;128:110316.

16. Tong T, Wu Y-Q, Ni W-J, Shen A-Z, Liu S. The potential insights of Traditional Chinese Medicine on treatment of COVID-19. Chinese Medicine. 2020;15(1):51.

17. Ren $X$, Shao X-X, Li X-X, Jia X-H, Song T, Zhou W-Y, Wang P, Li Y, Wang X-L, Cui Q-H, Qiu P-J, Zhao Y-G, Li X-B, Zhang F-C, Li Z-Y, Zhong Y, Wang Z-G, Fu X-J. Identifying potential treatments of COVID-19 from Traditional Chinese Medicine (TCM) by using a data-driven approach. J Ethnopharmacol. 2020;258:112932.

18. Mi DH, Fang HJ, Zheng GH, Liang XH, Ding YR, Liu X, Liu LP. DPP-4 inhibitors promote proliferation and migration of rat brain microvascular 
endothelial cells under hypoxic/high-glucose conditions, potentially through the SIRT1/HIF-1/NEGF pathway. CNS Neurosci Ther. 2018;25(3):323-32.

19. Tong $X L$, Li XY, Zhao LH, Li QW, Yang YY, Lin YQ, Ding QY, Lei Y, Wang $Q$ Song B, Liu WK, Shen SW, Zhu XD, Huang FJ, Zhou YD. Discussion on Traditional Chinese Medicine Prevention and Treatment Strategies of Coronavirus Disease 2019 (COVID-19) from the Perspective of "Colddampness Pestilence". J Tradit Chin Med. 2020;06:465-70.

20. National Health Commission of the People's Republic of China. Diagnosis and Treatment Protocol for COVID-19(Trial Version 6). http://www.nhc. gov.cn/yzygj/s7653p/202002/8334a8326dd94d329df351d7da8aef c2.shtml (Accessed on 19 February 2020).

21. National Health Commission of the People's Republic of China. Diagnosis and Treatment Protocol for COVID-19 (Trial Version 7). http://www. nhc.gov.cn/yzygj/s7653p/202003/46c9294a7dfe4cef80dc7f5912eb19 89.shtml (Accessed on 4 March 2020).

22. National Administration of Traditional Chinese Medicine. The general formula - community - Internet academician Tong Xiaolin: the importance of TCM anti epidemic. http://www.satcm.gov.cn/xinxifabu/meitibaoda o/2020-03-27/14297.html (Accessed on 27 March 2020).

23. Xu J, Wang F, Guo JJ, Xu CS, Cao YZ, Fang ZL, Wang QW. Pharmacological Mechanisms Underlying the Neuroprotective Effects of Alpinia oxyphylla Miq on Alzheimer's Disease. Int J Mol Sci. 2020;21 (6):2071.

24. Ding ZH, Zhong RX, Yang YN, Xia TY, Wang WJ, Wang Y, Xing N, Luo Y, Li SY, Shang LF, Shu ZP. Systems pharmacology reveals the mechanism of activity of Ge-Gen-Qin-Lian decoction against LPS-induced acute lung injury: a novel strategy for exploring active components and effective mechanism of TCM formulae. Pharmacol Res. 2020;156:104759.

25. Xue RC, Fang Z, Zhang MX, Yi ZH, Wen CP, Shi TL. TCMID: traditional Chinese Medicine integrative database for herb molecular mechanism analysis. Nucleic Acids Res. 2013;41(D1):D1089-95.

26. Ru JL, Li P, Wang JN, Zhou W, Li BH, Huang C, Li PD, Guo ZH, Tao WY, Yang YF, XU X, Li Y, Wang YH, Yang L. TCMSP: a database of systems pharmacology for drug discovery from herbal medicines. Journal of Cheminformatics. 2014;6(1):13.

27. Daina A, Michielin O, Zoete V. SwissADME: a free web tool to evaluate pharmacokinetics, drug-likeness and medicinal chemistry friendliness of small molecules. Scientific Reports. 2017;7(1):42717.

28. Kim S, Chen J, Cheng TJ, Gindulyte A, He J, He SQ, Li QL, Shoemaker BA, Thiessen PA, Yu B, Zaslavsky L, Zhang J, Bolton EE. PubChem 2019 update: improved access to chemical data. Nucleic Acids Res. 2018:47(D1):D1102-9.

29. Keiser MJ, Roth BL, Armbruster BN, Ernsberger P, Irwin JJ, Shoichet BK. Relating protein pharmacology by ligand chemistry. Nat Biotechnol. 2007;25(2):197-206.

30. Faurie C, Williams N, Cundy PJ. A stitch in time: stitching errors in digital radiology. The Medical journal of Australia. 2017;207(5):224.

31. Consortium, TU. Reorganizing the protein space at the Universal Protein Resource (UniProt). Nucleic Acids Res. 2011;40(D1):D71-5.

32. Rappaport N, Fishilevich S, Nudel R, Twik M, Belinky F, Plaschkes I, Stein TI, Cohen D, Oz-Levi D, Safran M, Lancet D. Rational confederation of genes and diseases: NGS interpretation via GeneCards, MalaCards and VarElect. BioMed Eng OnLine. 2017:16(1):72.

33. Szklarczyk D, Gable AL, Lyon D, Junge A, Wyder S, Huerta-Cepas J, Simonovic M, Doncheva NT, Morris JH, Bork P, Jensen LJ, Christian V. STRING v11: protein-protein association networks with increased coverage, supporting functional discovery in genome-wide experimental datasets. Nucleic Acids Res. 2018;47(1):607-13.

34. Shannon P, Markiel A, Ozier O, Baliga NS, Wang JT, Ramage D, Amin N, Schwikowski B, Ideker T. Cytoscape: a software environment for integrated models of biomolecular interaction networks. Genome Res. 2003;13(11):2498-504

35. Li M, Li DY, Tang Y, Wu FX, Wang JX. CytoCluster: a cytoscape plugin for cluster analysis and visualization of biological networks. Int J Mol Sci. 2017;18(9):1880

36. Chin $\mathrm{CH}$, Chen $\mathrm{SH}, \mathrm{Wu} H \mathrm{H}, \mathrm{Ho} \mathrm{CW}$, Ko MT, Lin CY. cytoHubba: identifying hub objects and sub-networks from complex interactome. BMC Syst Biol. 2014:8(4):S11.

37. O'Boyle NM, Banck M, James CA, Morley C, Vandermeersch T, Hutchison GR. Open Babel: an open chemical toolbox. Journal of Cheminformatics. 2011:3(1):33.
38. Berman H, Henrick K, Nakamura H. Announcing the worldwide Protein Data Bank. Nat Struct Mol Biol. 2003;10(12):980.

39. Trott O, Olson AJ. AutoDock Vina: improving the speed and accuracy of docking with a new scoring function, efficient optimization, and multithreading. J Comput Chem. 2010;31(2):455-61.

40. Yuan SG, Chan HCS, Filipek S, Vogel H. PyMOL and inkscape bridge the data and the data visualization. Structure. 2016;24(12):2041-2.

41. Molecular Operating Environment (MOE) software. Chemical Computing Group Inc. https://www.chemcomp.com/Products.htm (Accessed on last accessed May 2020).

42. Jing YF. Research on material basis and related pharmacodynamics of coked Chinese Hawthorn based on traditional efficacy. Chengdu University of Traditional Chinese Medicine, 2012.

43. Nie CX. Study on the differences of Chemical constituents and Lipidlowering and digestion-promoting effects of different processed of Hawthorn based on ${ }^{1} \mathrm{H}-\mathrm{NMR}$ Metabonomics. Shanxi University of Chinese Medicine, 2019.

44. Xu Y. Study on the "coke aroma" material basis that promote digestion and the synergistic mechanism of "Jiao San Xian" after charred Southwest Jiaotong University, 2018.

45. Ling JH. Studies on the Chemical Constituents and the Processing Procedures of Malt. Shenyang Pharmaceutical University, 2005.

46. Sun H, Liang J, Zhang M-Q, Xia M-Q, Lan Z-L, Wan J, Zhou X. Historical evolution and modern research of Hordei Fructus Germinatus processing. J Guangdong Pharm Univ. 2018;34(2):254-7.

47. Klok FA, Kruip MJ, van der Meer NJM, Arbous MS, Gommers PJ, Kant KM, Kaptein FHJ, van Paassen J, Stals MAM, Huisman MV, Endeman H. Incidence of thrombotic complications in critically ill ICU patients with COVID-19. Thromb Res. 2020;191:145-7.

48. Violi F, Pastori D, Cangemi R, Pignatelli P, Loffredo L. Hypercoagulation and antithrombotic treatment in coronavirus 2019: a new challenge. Thromb Haemost. 2020;120(6):949-56.

49. González-Pinto T, Luna-Rodríguez A, Moreno-Estébanez A, Agirre-Beitia G, Rodríguez-Antigüedad A, Ruiz-Lopez M. Emergency room neurology in times of COVID-19: malignant ischemic stroke and SARS-COV2 infection. Eur J Neurol. 2020. https://doi.org/10.1111/ene.14286.

50. Curcio MF, Batista WL, Castro ED, Strumillo ST, Ogata FT, Alkmim W, Brunialti MKC, Salomão R, Turcato G, Diaz RS, Monteiro HP, Janini LMR. Nitric oxide stimulates a PKC-Src-Akt signaling axis which increases human immunodeficiency virus type 1 replication in human T lymphocytes. Nitric Oxide. 2019;93:78-89.

51. Otano I, Alvarez M, Minute L, Ochoa MC, Migueliz I, Molina C, Azpilikueta A, de Andrea CE, Etxeberria I, Sanmamed MF, Teijeira Á, Berraondo P, Melero I. Human CD8 T cells are susceptible to TNF-mediated activationinduced cell death. Theranostics. 2020;10(10):4481-9.

52. Lin YT, Liu W, He Y, Wu YL, Chen WN, Lin XJ, Lin X. Hepatitis B Virus X Protein Increases 8-Oxo-7,8-Dihydro-2'-Deoxyguanosine (8-Oxodg) Level via Repressing MTH1/MTH2 Expression in Hepatocytes. Cell Physiol Biochem. 2018;51(1):80-96

53. Weider T, Richardson SJ, Morgan NG, Paulsen TH, Dahl-Jørgensen K, Hammerstad SS. Upregulation of HLA Class I and Antiviral Tissue Responses in Hashimoto's Thyroiditis. Thyroid. 2020;30(3):432-42.

54. Parekh NJ, Krouse TE, Reider IE, Hobbs RP, Ward BM, Norbury CC. Type I interferon-dependent CCL4 is induced by a CGAS/STING pathway that bypasses viral inhibition and protects infected tissue, independent of viral burden. PLoS Pathog. 2019;15(10):e1007778.

55. Ma ZY, Zhang EJ, Gao SC, Xiong Y, Lu MJ. Toward a functional cure for Hepatitis $B$ : the rationale and challenges for therapeutic targeting of the B cell immune response. Front Immunol. 2019;10:2308.

56. Wong R, Bhattacharya D. Basics of memory B-cell responses: lessons from and for the real world. Immunology. 2019;156(2):120-9

57. Mahallawi WH, Khabour OF, Zhang Q, Makhdoum HM, Suliman BA. MERSCoV infection in humans is associated with a pro-inflammatory Th1 and Th17 cytokine profile. Cytokine. 2018;104:8-13.

58. Wong CK, Lam CWK, Wu AKL, I I WK, Lee NLS, Chan IHS, Lit LCW, Hui DSC, Chan MHM, Chung SSC, Sung JJY. Plasma inflammatory cytokines and chemokines in severe acute respiratory syndrome. Clin Exp Immunol. 2004;136(1):95-103.

59. Bowie AG, Unterholzner L. Viral evasion and subversion of pattern-recognition receptor signalling. Nat Rev Immunol. 2008;8(12):911-22. 
60. Cheung CY, Poon LLM, Ng IHY, Luk W, Sia S-F, Wu MHS, Chan K-H, Yuen K-Y, Gordon S, Guan Y, Peiris JSM. Cytokine responses in severe acute respiratory syndrome coronavirus-infected macrophages in vitro: possible relevance to pathogenesis. J Virol. 2005;79(12):7819-26.

61. Felsenstein S, Herbert JA, McNamara PS, Hedrich CM. COVID-19: immunology and treatment options. Clinical Immunology. 2020;215:108448.

62. Sordo-Bahamonde C, Vitale M, Lorenzo-Herrero S, López-Soto A, Gonzalez S. Mechanisms of resistance to NK cell immunotherapy. Cancers. 2020;12(4):893.

63. Schwartz SL, Cleyrat C, Olah MJ, Relich PK, Phillips GK, Hlavacek WS, Lidke KA, Wilson BS, Lidke DS. Differential mast cell outcomes are sensitive to FceRI-Syk binding kinetics. Mol Biol Cell. 2017;28(23):3397-414.

64. Savvides SN, Elewaut D. Small-molecule inhibitors get pro-inflammatory TNF into shape. Nat Rev Rheumatol. 2020;16(4):189-90.

65. Zhu GQ, Zhao GQ, Lin J, Li C, Wang Q, Xu Q, Peng XD, Zheng HR. FCN-A mediates the inflammatory response and the macrophage polarization in Aspergillus fumigatus keratitis of mice by activating the MAPK signaling pathway. Int Immunopharmacol. 2020;83:106473.

66. Sukocheva OA, Lukina E, McGowan E, Bishayee A, Chapter Four - Sphingolipids as mediators of inflammation and novel therapeutic target in inflammatory bowel disease. In Advances in Protein Chemistry and Structural Biology, Donev, R., Ed. Academic Press: 2020; Vol. 120, pp 123-158.

67. Zhu LH, She ZG, Cheng X, Qin JJ, Zhang XJ, Cai JJ, Lei F, Wang HT, Xie J, Wang WX, Li HM, Zhang P, Song XH, Chen X, Xiang M, Zhang CZ, Bai LJ, Xiang D, Chen MM, Liu YQ, Yan YQ, Liu MY, Mao WM, Zou JJ, Liu LM, Chen GH, Luo PC, Xiao B, Zhang CJ, Zhang ZX, Lu ZG, Wang JH, Lu HF, Xia XG, Wang DH, Liao XF, Peng G, Ye P, Yang J, Yuan YF, Huang XD, Guo J, Zhang BH, Li HL. Association of blood glucose control and outcomes in patients with COVID-19 and pre-existing type 2 diabetes. Cell Metab. 2020;31:1-10.

68. Zhang HB, Penninger JM, Li YM, Zhong NS, Slutsky AS. Angiotensinconverting enzyme 2 (ACE2) as a SARS-CoV-2 receptor: molecular mechanisms and potential therapeutic target. Intensive Care Med. 2020;46(4):586-90.

69. Zhou P, Yang XL, Wang XG, Hu B, Zhang L, Zhang W, Si HR, Zhu Y, Li B, Huang CL, Chen HD, Chen J, Luo Y, Guo H, Jiang RD, Liu MQ, Chen Y, Shen $X R$, Wang $X$, Zheng XS, Zhao K, Chen QJ, Deng F, Liu LL, Yan B, Zhan FX, Wang YY, Xiao GF, Shi ZL. A pneumonia outbreak associated with a new coronavirus of probable bat origin. Nature. 2020;579(7798):270-3.

70. Yi HY, Zhang Y, Yang XF, Li MY, Hu HF, Xiong J, Wang N, Jin JY, Zhang YS, Song $Y$, Wang $X$, Chen LH, Lian JQ. Hepatitis B core antigen impairs the polarization while promoting the production of inflammatory cytokines of M2 macrophages via the TLR2 pathway. Front Immunol. 2020;11:535.

71. Wen J, Wang YT, Valentine KM, Dos Santos Alves RP, Xu Z, Regla-Nava JA, Ngono AE, Young MP, Ferreira LCS, Shresta S. CD4 T cells cross-reactive with dengue and zika viruses protect against zika virus infection. Cell reports. 2020;31(4):107566.

72. Simula L, Corrado M, Accordi B, Di Rita A, Nazio F, Antonucci Y, Di Daniele A, Caicci F, Caruana I, Soriano ME, Pigazzi M, Locatelli F, Cecconi F, Campello S. JNK1 and ERK1/2 modulate lymphocyte homeostasis via BIM and DRP1 upon AICD induction. Cell Death Diff. 2020.

73. Verrico CD, Wesson S, Konduri V, Hofferek CJ, Vazquez-Perez J, Blair E, Dunner KJ, Salimpour P, Decker WK, Halpert MM. A randomized, double-blind, placebo-controlled study of daily cannabidiol for the treatment of canine osteoarthritis pain. Pain. 2020 (articles in Press).

74. Xiao P, Zhang H, Zhang Y, Zheng M, Liu R, Zhao Y, Zhang X, Cheng H, Cao Q, Ke Y. Phosphatase Shp2 exacerbates intestinal inflammation by disrupting macrophage responsiveness to interleukin-10. J Exp Med. 2019;216(2):337-49.

75. McKinstry KK, Strutt TM, Buck A, Curtis JD, Dibble JP, Huston G, Tighe M, Hamada H, Sell S, Dutton RW, Swain SL. IL-10 deficiency unleashes an influenza-specific Th17 response and enhances survival against highdose challenge. J Immunol. 2009;182(12):7353-63.

76. Metzemaekers M, Vandendriessche S, Berghmans N, Gouwy M, Proost P. Truncation of CXCL8 to CXCL8(9-77) enhances actin polymerization and in vivo migration of neutrophils. J Leukoc Biol. 2020;107(6):1167-73.

77. Ferrara F, Woodby B, Pecorelli A, Schiavone ML, Pambianchi E, Messano $\mathrm{N}$, Therrien J-P, Choudhary H, Valacchi G. Additive effect of combined pollutants to UV induced skin OxInflammation damage Evaluating the protective topical application of a cosmeceutical mixture formulation. Redox Biology. 2020;34:101481.

78. Fajgenbaum DC. Novel insights and therapeutic approaches in idiopathic multicentric Castleman disease. Hematology. 2018;2018(1):318-25.

79. Wang X, Miller EB, Goswami M, Zhang P, Ronning KE, Karlen SJ, Zawadzki RJ, Pugh EN, Burns ME. Rapid monocyte infiltration following retinal detachment is dependent on non-canonical IL6 signaling through gp130. J Neuroinflam. 2017;14(1):121.

80. Liu B, Li M, Zhou Z, Guan X, Xiang Y. Can we use interleukin-6 (IL-6) blockade for coronavirus disease 2019 (COVID-19)-induced cytokine release syndrome (CRS). J Autoimmun. 2020;2020:102452.

81. Gubernatorova EO, Gorshkova EA, Polinova AI, Drutskaya MS. IL-6: relevance for immunopathology of SARS-CoV-2. Cytokine Growth Factor Rev. 2020;53:13-24.

82. Han H, Ma Q, Li C, Liu R, Zhao L, Wang W, Zhang P, Liu X, Gao G, Liu F, Jiang Y, Cheng X, Zhu C, Xia Y. Profiling serum cytokines in COVID-19 patients reveals IL-6 and IL-10 are disease severity predictors. Emerg Microb Infect. 2020;9(1):1123-30.

83. Saghazadeh A, Rezaei N. Towards treatment planning of COVID-19: rationale and hypothesis for the use of multiple immunosuppressive agents: anti-antibodies, immunoglobulins, and corticosteroids. Int Immunopharmacol. 2020;84:106560.

84. Kaur S, Bansal Y, Kumar R, Bansal G. A panoramic review of IL-6: structure, pathophysiological roles and inhibitors. Bioorg Med Chem. 2020;28(5):115327.

85. Chen $X \mathrm{H}$, Zhao BH, Qu YM, Chen YR, Xiong J, Feng Y, Men D, Huang QC, Liu Y, Yang B, Ding JY, Li F. Detectable serum SARS-CoV-2 viral load (RNAaemia) is closely correlated with drastically elevated interleukin 6 (IL-6) level in critically ill COVID-19 patients. Clin Infect Dis. 2020 (articles in Press)

\section{Publisher's Note}

Springer Nature remains neutral with regard to jurisdictional claims in published maps and institutional affiliations.

Ready to submit your research? Choose BMC and benefit from

- fast, convenient online submission

- thorough peer review by experienced researchers in your field

- rapid publication on acceptance

- support for research data, including large and complex data types

- gold Open Access which fosters wider collaboration and increased citations

- maximum visibility for your research: over $100 \mathrm{M}$ website views per year

At BMC, research is always in progress.

Learn more biomedcentral.com/submissions 